the student has neither a definite knowledge of the physiologic action of water, which can only be gained by practical experience, nor the understanding of its intelligent application in diseased conditions. The effect of heat in all its variations of temperature, with such a wide range of therapeutic uses, is of both scientific and cliuical importance.

F'hysico-mechanical therapeutics, which embraces medical gymnastics and massage, with some forms of the application of clectricity, is not less important than the other two subjects, and what mav be said in regard to the lack of proper training and instruction in these two may apply to the other.

Practical dietctics can not be universally introduced without the free use of hospitals equipped with dietetic kitchens; but in schools where such hospital facilities are at hand, a section of the class could take its turn under a competent instructor, certain hours in the day, during the week, in acquiring the accurate know!ledge of the preparation of foods and their proper administration in the cases being treated in the institution. The effects could then be readijy appreciated by actual demonstrition; and thus another and most important element would be added to the skill of the future practitioner.

No objection, however, can be urged against the illustrative method of teaching hydrotherapy and physicomechanical therapenties. Every school is equipped with college dispensaries. All that is needed is to arrange a room, or suite of rooms, equipped with the necessary appliances for the application of water in various forms, and with the different mechanical apparatus to be used. T'hese arrangements may be as claborate or simple as the school can afford. A separate, or adjoining room may be equipped for placing the patient where he may obtain the benefits of the various forms of physico-mechanical iherapeutics. In the customary division of students into sections, for the different dispensary classes, a certain number can readily be allotted to cach of the rooms above mentioned, just as they are assigned now to the rooms for instruction in surgery, gynecology, nervous diseases, rcneral medicine, dermatology, etc. The clinical material may come direct, or may be referred from the other departments of the institution. Students will gain more exact knowledge by being called upon to assist the instructor in his daily work; and more patients cin be treated when the students are turned into assistant5--which is a double gain. This method would not trespass on the time allotted to other work, or unduly press upon the strength of the student; and therefore it would appear to be perfectly feasible. As the value and practicability of the subjects we have been considering become further recognized by the facultie: of our medical schools, special elective courses may be established, under trained instructors, in order to give the student theoretical and practical teaching combined. The writer has found in his own experience in teaching that these practical methods are easicr for the student. They give him an opportunity to learn more accurately by actual observation and experience, associating the clinical importance of the case with the therapeutic measures used.

It will thus be seen that such observation and experience will help the student to comprehend the pathologic condition of the patient-whether a medical or surgical case, and he is better enabled to grasp the clinical and scientific phenomena presented to his mind. The sig- nificance of medical teaching will become real, better understood and more easily remembered. The accumulated facts obtained from didactic teaching will also thus be better utilized, and the mind stimulated for further investigation and study.

364 Dearborn Avenue.

\section{THE SEMINAR METHOD IN MEDICAL} TEACHING.

BAYARD HOLMES, M.D.

1'rofessor of Surgery and Clinical Surgery in the University of Illinois.

chicagu.

The present is a time of great change in methods, as well as in the principles of pedagogy in our medical schools. The extent of medical science is so great that no individual can expect to be master of the whole field. The duration of the course preparatory to the practice, of medicine is now long enough, and the preliminary education is now thorough enough to allow the best methods of study to be used. For a certain part of the medical curriculum there is no plan of teaching which promises so mich as the seminar.

In previous publications ${ }^{1}$ I have called attention to my own efforts in this direction. It is my purpose here to make another plea for the more general adoption of the seminar, in teaching almost any topic of interest so we student.

In order that we may understand each other, let me say that the seminar is a method in which each member of the class does independent laboratory, clinical or library work on a subtopic of general interest to the class as a whole, this subtopic chosen by the student or assigned by the teacher. The seminar is a meeting of the students and the teacher to hear, question, criticise and discuss the work of individuals. When the seminar meets for the first time the teacher presents the general subject in the form of a lecture, in the course of which the whole topic is outlined and interesting questions are put forward. From these questions and the outline, and from a knowledge of the individual members of the class, the assignments of subtopics are made. A student takes his assignment and studies up the question, and at the next or some subsequent meeting of the seminar, he presents to the class in such a manner as the case requires, the results of his study. This time it may be an analysis and blackboard talk, the next time a carefully-written abstract, then again a microscopic demonstration and written paper. or later and more complete than any of these, a finished thesis. During the presentation the student who has the floor is in the position of the teacher. The teacher for the moment becomes one of the students. At any moment during the presentation questions may be asked or explanation required. At the end criticsms are to be expected. Such exercises, like laboratory investigation, are time-consuming. The student should have not less than one-half his daily study time for a seminar of two hours a week. The seminar class should not exceed 20 students, selected by their interest in a topic or in the teacher. The management of larger classes is limited to unusual teachers and special topics and methods of procedure. In a very limited field I have used the seminar with a class of 150 students.

The seminar presupposes an elective course. In no other way can the student have time for the exhaustive

1. Holmes, Bayard: "The Seminary Method in Teaching Surg erv." The Journat A. M. A., Aug. 8. 1896, et seq. 
study of a limited number of subjects. The student will, however, be bound to learn in the course of this study most of the general information which lectures and text-book study is intended to teach. 'The seminar' requires an open library of current and standard medical literature and an ability on the part of the student to make economical use of it. The library must be open during all reasonable study hours, e. g.. from 8 a. m. to 10 p. m., and it must be thoroughly catalogued even down to the monographs and important articles in the serials. It will often, in the course of a study, be necessary to get material from the Surgeon General's Library and even to make purchases, and provision should be made for these contingencies so that there will be no paralyzing delay. The laboratories, museums, collections, clinics and other equipment of the college must be at ready and unobstructed, even helpful, disposal of the student. If the student has for his topic the appearance of fat necrosis in gallstone disease, he may require not only the literature from the library, specimens from the museum and laboratory, but he may need to undertake considerable correspondence with pathologists and surgeons, and even wait for autopsies or operation specimens.

The seminar is certainly a poor method at the beginning for the bottle-fed incompetents of our compulsory, graded medical course, but many of them even grow and thrive under the exercise and liberty of the seminar and in moments of forgetfulness manifest the ardor of enthusiasm. But there are always some in every class who bear with difficulty the straitjacket of a required course and the lockstep of class instruction, and these erratic men are the delight of the seminar. They plunge with fervor into their subject and devour the literature. They seek on the cadaver or at the operation table the positive anatomical knowledge which their topic requires. They leave no stone unturned which promises the least elucidation of the subject, and they present the results of their study to the class in a convincing argument and with a persuasive enthusiasm.

There are, of course, certain conditions which the student must meet. He must have a motive for study based for the most part upon a considerable amount of bedside experience. Unless the student is actually in the position of the physician with the immediate obligation to cure the patient safely, quickly and pleasantly, he does not possess the strongest, truest and surest motive for study. When this motive is lacking it can often be supplied by giving the student the necessary patient. or by taking such a topic as the student has already met in his practice. When all other means fail, the student's own ailments or deformities may secure the necessary interest.

The student must also have such a preliminary literary training as will make his routine work perfect in form and availability. It is necessary sometimes to secure at the beginning a chirography suitable to such accurate and manageable work as this form of study demands. Every page must be written as perfectly as if for the printer. The slipshod penmanship which the ordinary note-taking in our medical schools begets, entirely precludes the idea of good work. The student must, from the first. do all his work neatly, in an orderly manner and completely, so that it may never require revision or correction. It is only by writing a library hand or something approaching it that good literary work of such a technical character as medicine requires ran be satisfactorily done.
The student must know how to use the library. Only a rare librarian can put students in the way of using the library independently. The shelves as well as the catalogue should be accessible to students. The stacks should be in alcoves, with tables and writing material handy: so that the student, after his ability to find them and replace them has been established, can easily consult many books without troubling the librarian. The same may be said of the laboratory and museum. In order that the student may master his subject completely he must be able, if the subject requires it, to study the anatomy of the part concerned in a thoroughly equipped anatomic laboratory, in the pathologic laboratory and in the autopsy room. In fact, the seminar method of study presupposes for its fullest utilization a complete co-ordination and co-operation of all the resources of the medical school. Through its best and freest use the student becomes an investigator of the topic in his hand, of the literature of the various aspects of his subject, and incidentally of the history of medicine itself. The studen $\mathrm{is}$ put or puts himself in the position which he will occupy after he leaves the school when he attempts to study any medical topic suggested by the requirements of his practice.

Last of all, through the seminar, the medical teacher may secure for the profession the careful literary and experimental study of a large and growing number of subjects which he can never have time to follow out by himself, and he may be instrumental in bringing these subjects before the profession through his students' theses. A considerable number of the most valuable contributions to medical literature comes to us now through the theses of applicants for the doctor's degree in foreign universities. The American students are not less talented or diligent. Our teachers are not less devoted. The continuous course which many medical schools are adopting promises that the end of the course shall be punctuated by the return to the discarded thesis. To make the thesis possible or valuable a considerable portion of the curriculum must be conducted on the seminar plan, whether it is called by that name or not.

\section{MEDICAL EDUCATION.* \\ J. R. JONES, M.D. \\ WINNIPEC, MANITOBA.}

The writer, after considering the several phases of the sul. ject of medical education, registration, etc., as they apply in Canada, said:

PROFESSIONAI. EDCCATION

The medical curriculum has subjects difficult to acquire worthless as mental gymnastics, useless in practice and speedily forgotten when acquired. The methods of teaching are imperfect and vicious. The student in didactic lectures is not taught-he is over-lectured and under-taught. The lecturer describes rather than demonstrates and instead of making the student follow him step by step in his methods of observation, collecting, comparing, testing, and recording facts and of reasoning thereon, the didactic lecturer leaves them to be learned by being described, forgetful that they can be learned only by being practiced.

The main tendency of the present method of didactic lectures is to give students smatterings of scientific knowledge at the cost of that thorough knowlerge of their art which is essen. tial to its successful exercise. In the curriculum there is overlapping of similar subjects in the didactic and clinical courses. The course of didactic lectures should be entirely abolished or radically modified. 'Teaching should be bedside

* Abstract of the Address in Medicine, delivered before the Canadian Medical Association, Winnipeg, August 28 